\title{
Abstract
}

\section{Use of Cytology to Diagnose Inherited Breast Cancer}

Pål Møller ${ }^{1}$, Gareth Evans ${ }^{2}$, Elaine Anderson ${ }^{3}$, Lovise Mæhle ${ }^{1}$, Fiona Lalloo $^{2}$, Ketil R. Heimdal ${ }^{1}$, and C. Michael Steel ${ }^{4}$, in cooperation with The Biomed 2 Demonstration Programme on Inherited Breast Cancer

${ }^{1}$ Unit of Medical Genetics, The Norwegian Radium Hospital, Norway

${ }^{2}$ Family History Clinic, Centre for Cancer Epidemiology, Christie Hospital NHS Trust, Withington, Manchester, UK ${ }^{3}$ Edinburgh Breast Unit, Western General Hospital NHS Trust, Edinburgh, UK ${ }^{4}$ School of Biomedical Sciences, University of St Andrews, Fife and Edinburgh Healthcare NHS Trust, UK

There appears to be no report on the use of invasive procedures (fine needle aspiration or core biopsies) in high-risk clinics dedicated to early diagnosis and treatment of inherited breast cancer. Such information is required for various reasons: It is requested by the patient at genetic counselling, it is a putative capacity problem at the departments examining the specimens, and it should be included in cost/benefit analysis of the total set-up for health purchasers.

All examinations at the collaborating highrisk clinics during a defined period were registered with respect to total number of clinical/mammographic investigations, use of cytology/histology (FNA or core biopsies), and number of prospectively detected cancers.

Numbers of invasive procedures were low, and a significant proportion of those subjected to such examinations actually had cancer. The prevalences in the different clinics were close to identical. Indications for invasive procedures are well established and lead to similar use and outcome at the different clinics.

Table 1

Results

\begin{tabular}{lccc}
\hline & Norway & Manchester & Edinburgh \\
\hline prevalence of cytology/examination & $3.9 \%$ & $4.2 \%$ & $7.3 \%$ \\
prevalence of (CIS or cancer)/cytology & $16.7 \%$ & $12.0 \%$ & $11.3 \%$ \\
\hline
\end{tabular}




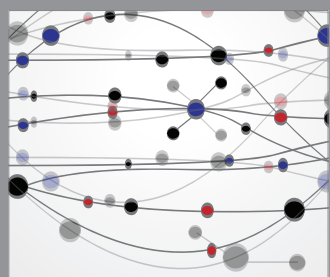

The Scientific World Journal
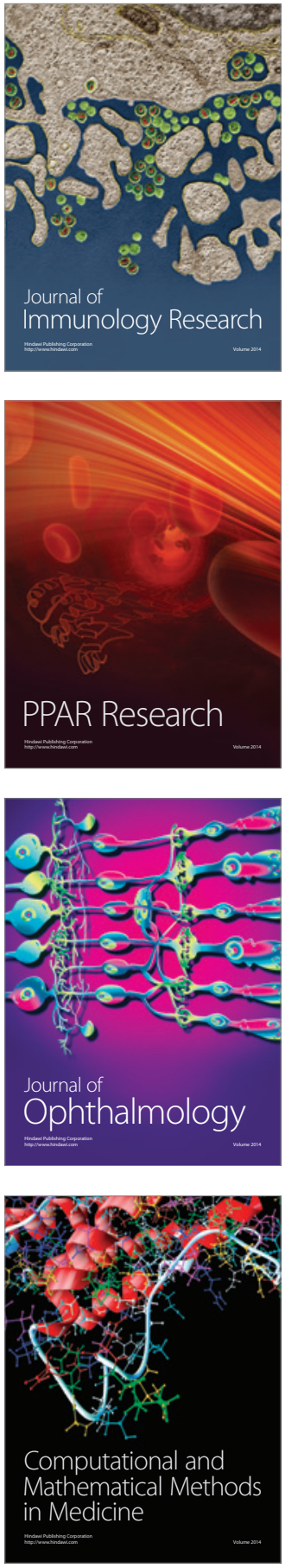

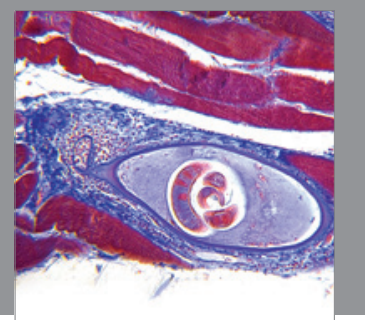

Gastroenterology

Research and Practice
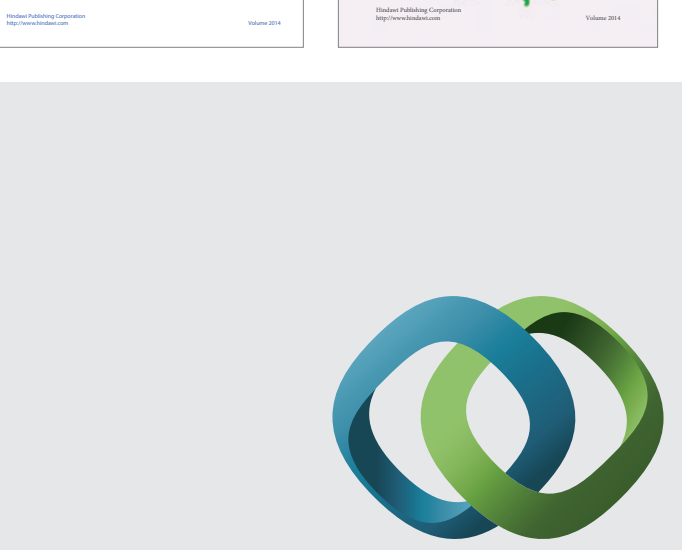

\section{Hindawi}

Submit your manuscripts at

http://www.hindawi.com
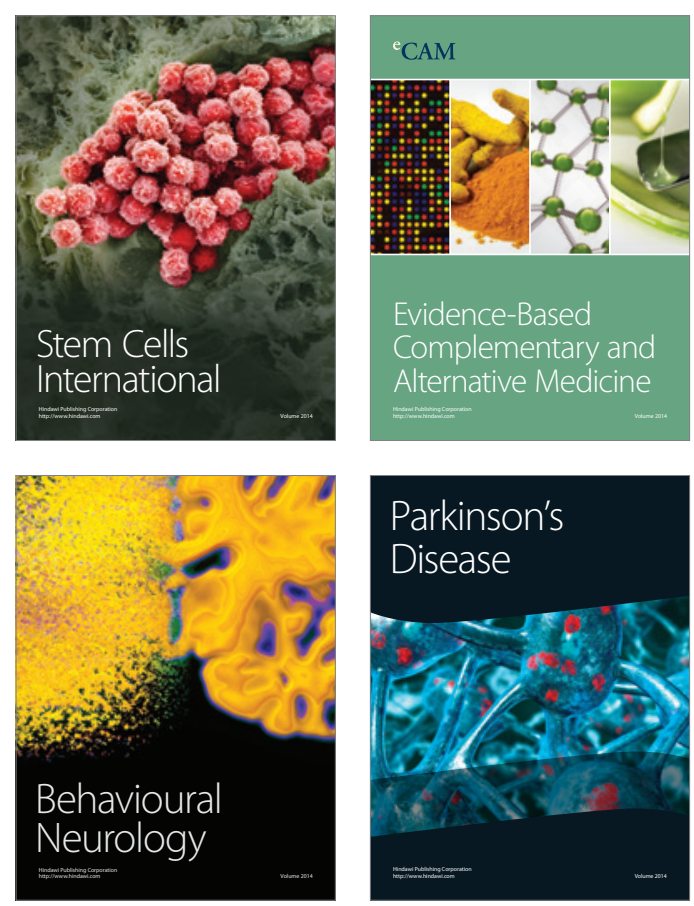

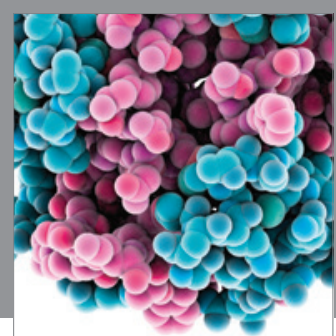

Journal of
Diabetes Research

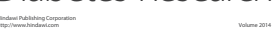

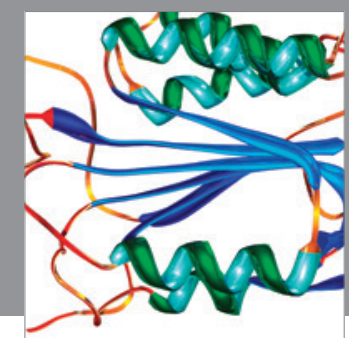

Disease Markers
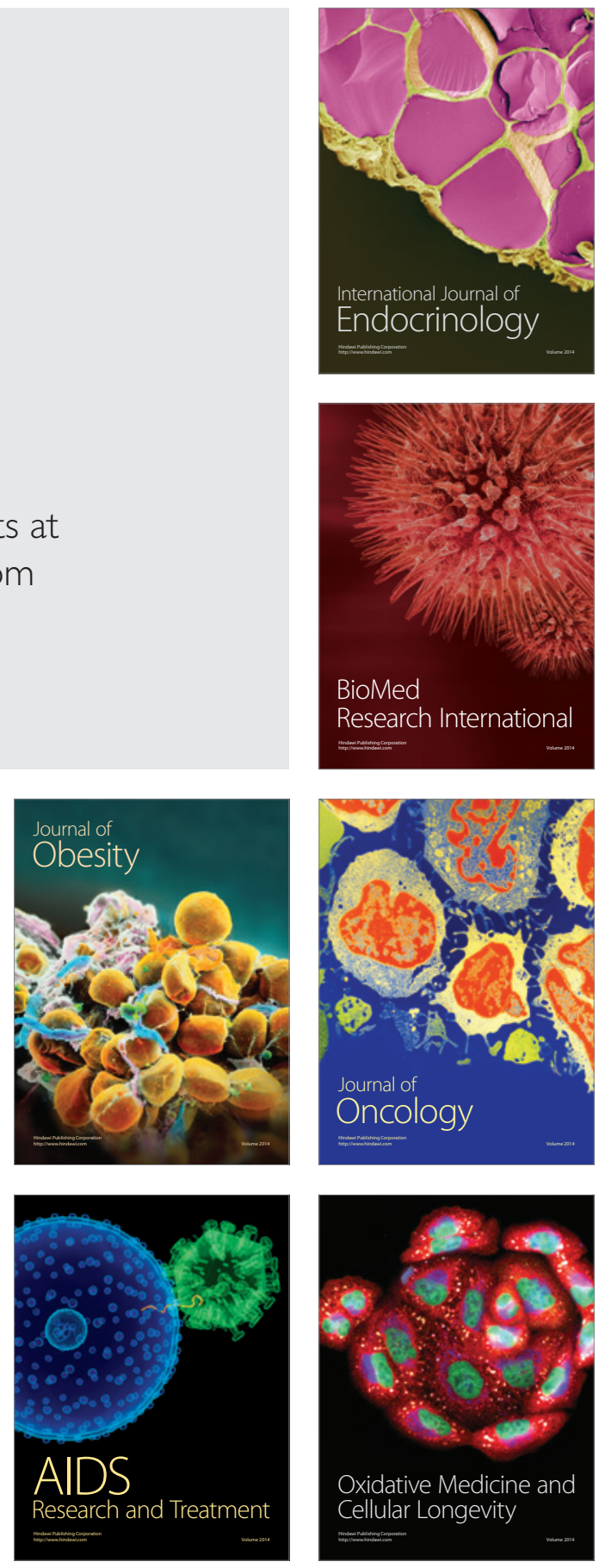